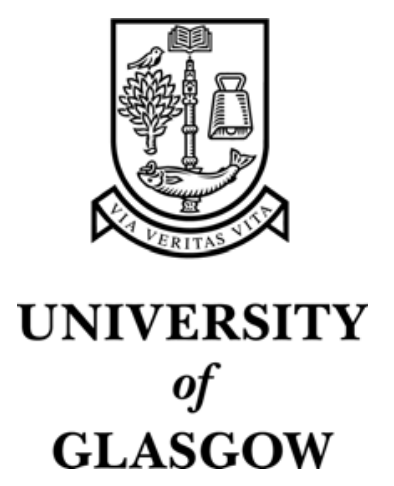

Macpherson, F. (2006) Ambiguous figures and the content of experience. Nous 40(1):pp. 82-117.

http://eprints.gla.ac.uk/3323/ 


\title{
Ambiguous Figures and the Content of Experience
}

\author{
Fiona MACPHERSON \\ University of Glasgow
}

\begin{abstract}
Representationalism is the position that the phenomenal character of an experience is either identical with, or supervenes on, the content of that experience. Many representationalists hold that the relevant content of experience is nonconceptual. I propose a counter-example to this form of representationalism that arises from the phenomenon of Gestalt switching, which occurs when viewing ambiguous figures. First, I argue that one does not need to appeal to the conceptual content of experience or to judgements to account for Gestalt switching. I then argue that experiences of certain ambiguous figures are problematic because they have different phenomenal characters but that no difference in the nonconceptual content of these experiences can be identified. I consider three solutions to this problem that have been proposed by both philosophers and psychologists and conclude that none can account for all the ambiguous figures that pose the problem. I conclude that the onus is on representationalists to specify the relevant difference in content or to abandon their position.
\end{abstract}

\section{Introduction}

Traditionally a distinction has been made between the representational elements of perceptual experience and the phenomenal character of perceptual experience. Lately, and in contrast to the traditional picture, many philosophers have argued that the phenomenal character of experience (that in virtue of which there is 'something that it is like' to undergo that experience $^{1}$ ) is identical with, or is determined by, the content of experience (that is, by what the experience represents). Substantial versions of these representational theories provide plausible naturalistic theories of representation. This is because providing such a theory allows one to see how a (c) 2006, Copyright the Authors

Journal compilation $\mathbb{0} 2006$, Blackwell Publishing, Inc. 
representationalist can give a naturalistic account of phenomenal character. If one identifies phenomenal character with content and one can provide a naturalistic theory of such content, one will thereby have provided a naturalistic theory of phenomenal character. A slightly more complicated story will have to be told if one holds that phenomenal character is merely determined by content but the thought is that the basics required for such an explanation are in place. If such a result could be established then a naturalistic answer to the problem of perceptual consciousness - one of the most tenacious problems in philosophy - would have been found.

Representationalist philosophers can either hold that the relevant representation is nonconceptual representation or is conceptual representation (or both). A perceptual state is said to represent nonconceptually, or equivalently, a perceptual state is said to have nonconceptual content, when it is legitimate to ascribe a perceptual state that represents the world to a subject and, at the same time, hold that the subject of the state need not possess the concepts required to specify the way in which the world is represented, that is, specify what the content is. A state has conceptual content otherwise. ${ }^{2}$ I think that there are substantial reasons to favour the nonconceptualist position over the conceptualist position but, nonetheless, I believe that the naturalistic, nonconceptualist, representationalist position faces insurmountable difficulties. ${ }^{3}$ In this paper, I examine one such difficulty for the naturalist, nonconceptualist position. This difficulty arises when one considers experiences of certain ambiguous figures.

Ambiguous figures are figures that when viewed can give rise to experiences that have different phenomenal characters. Moreover, these changes are not brought about by a change in the position of the figure relative to the viewer. I argue that some ambiguous figures give rise to experiences that differ in phenomenal character but that those experiences do not differ in nonconceptual content. If I am right, these experiences provide a counterexample to nonconceptualist representationalism.

Two important naturalistic, nonconceptual, representational theories of phenomenal character are the causal covariation theory and the teleological theory. Michael Tye and Fred Dretske, two leading representationalists, employ these theories in developing their representationalism. ${ }^{4}$ These versions of representationalism will be the primary targets of my discussion; however, I will also consider the problem more generally.

The structure of this paper is as follows. In section two, I will outline the main tenets of nonconceptual representationalism. In section three, there will be a preliminary discussion of ambiguous figures. I will present empirical evidence, which supports evidence from our own introspection, that certain kinds of figure (such as Mach's square/regular diamond) are ambiguous. In section four, I argue against the view that the Gestalt switch that happens when one looks at the relevant figures merely involves a change in judgement about the figure, rather than a change in the phenomenal 
character of one's experience. This claim has to be resisted in order to motivate the thought that the representationalist is committed to holding that there must be a difference in the content (matching the difference in phenomenal character) of the experiences of ambiguous figures. In section five, I argue that the traditional reasons for thinking that Gestalt switches must be accounted for in terms of differences in conceptual content are misguided. There is good reason to think that nonconceptual content should be able to account for ambiguous figures. Sections six and seven contain the most important arguments of this paper. I argue that one cannot hold that certain experiences of ambiguous figures have different contents if one ascribes to certain naturalistic theories of nonconceptual content. This result is backed up in section seven by considering and criticising a version of Peacocke's account of the nature of experiences of Mach's square/regulardiamond figure, which utilises the notion of protopropositional content. I also argue that some recent psychological studies carried out by Ferrante, Gerbino and Rock that may identify differences in the content of experiences of Mach's figure cannot be garnered to explain other similar ambiguous figures that present the same problem for naturalistic nonconceptual representationalists. Finally, I consider, but reject, a reply to my argument that invokes directional axes that are imposed upon experience.

\section{Representationalist Theories}

Naturalistic representational theories of phenomenal character ascribe contents to perceptual states. ${ }^{5}$ A state with content is something that is about, or represents, certain objects, properties or relations and has correctness conditions. $^{6}$ The paradigm cases of states with content are propositional attitudes, the contents of which are normally specified in 'that' clauses.

A notion of content similar to that ascribed to the propositional attitudes can be ascribed to visual experiences in the following manner. When someone has a visual experience it may seem to them that such and such is before them, and the proposition that specifies how things seem also demarcates the content of the experience. Thus, if Morag has a visual experience such that it seems to her that there is a yellow square to the left of an orange circle, then the content of that experience is that there is a yellow square to the left of an orange circle.

One might hold that the content being ascribed to visual experiences here is the same as the content ascribed to propositional attitudes because one might insist that if it seems to a subject that a yellow square is present, then the subject of the experience must have the ability to have the thought, or belief, that there is a yellow square present. One might insist that in experience it seems to a subject that an F is there if and only if they would believe that an $\mathrm{F}$ was there in the absence of countervailing considerations. According to this commonly held view, the way that the world seems to a subject when they are having an experience, when this is articulated by a 
'that' clause, is tied to a subject's cognitive abilities. ${ }^{7}$ Thus, on this view, this experiential content is conceptual because the subject is required to possess the concepts required to specify the content.

There are considerations, however, which might lead one to think that in fact visual experiences either do not have conceptual content or that they have, in addition, a more fundamental type of content: nonconceptual content. A state is said to have nonconceptual content when there is good reason to ascribe a state that represents the world to a subject and, at the same time, holds that the subject of the state need not possess the concepts required to specify the way in which the world is represented. These considerations fall into three main categories. First, people cannot hold in mind a specific shade of colour in order to reidentify that shade on another occasion. Human discriminatory powers are far more powerful than their powers of absolute identification, suggesting our stored representations of shades-and hence concepts of shades - are rather limited. ${ }^{8}$ (Of course one might come to possess a demonstrative concept of a shade of colour in virtue of experiencing it, but, plausibly, possession lasts only during the experience and for a very short interval afterwards.) Secondly, to best describe and explain a subject's behaviour there may be a pressure to ascribe to a subject a visual experience with a content, when the subject either lacks the concepts required to specify the content of the experience or is not a concept user at all. ${ }^{9}$ Such content must therefore be nonconceptual. Lastly, the contents of visual experience typically lack the inferential structure characteristic of states with conceptual content, such as belief states. This is not to say that the content of experience cannot combine with beliefs in inference to reach a conclusion the way the content of two beliefs might, rather it is to say that the content of experience will sometimes violate norms that are taken to be inviolable for belief content. For example, perceptual experiences (notably illusions), unlike beliefs, are often properly resilient to conclusive counter-evidence. One example is the Müller-Lyer illusion, where the horizontal lines continue to look different lengths even when one knows that they are the same length.
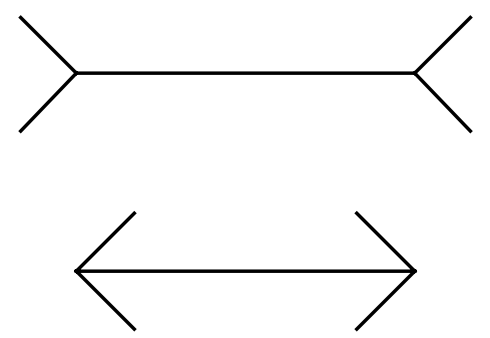

Müller-Lyer Illusion 
Moreover, there can be perceptions with explicitly contradictory content (as when one views impossible objects of the kind drawn by Escher and Reutersvärd), but it is often suggested that one cannot have a belief with a contradictory content. ${ }^{10}$ In so far as one can have an experience that represents the world while not possessing the concepts required to specify what is represented, then one can say that the content of the experience is nonconceptual.

There are good reasons, therefore, to think that visual experiences have nonconceptual content either instead of, or in addition to, conceptual content. Moreover, this approach is a theoretically valuable one if one believes that experiences and beliefs are very different kinds of state because, unlike experiences, beliefs lack phenomenal character. ${ }^{11}$ If this is a fact, one could explain it neatly by claiming that only nonconceptual content determines which phenomenal character a state has. Thus, as experiences have, and beliefs do not have, nonconceptual content, only the former will have phenomenal character.

Why do representationalists think that phenomenal character and content are identical or that phenomenal character supervenes on content? ${ }^{12}$ One reason is that if a subject has two visual experiences that differ in 'what it is like' for the subject of those experiences then, normally, these two experiences will be ascribed different contents. For example, the difference between what it is like to see a yellow square and what it is like to see an orange circle is mirrored by the fact that, in one experience, a yellow square is represented, in the other, an orange circle is represented. According to Michael Tye, the simplest explanation of why differences in phenomenal character are mirrored by differences in content is that phenomenal and representational properties are identical. ${ }^{13}$

A second reason that representationalists often cite is an alleged point about transparency, namely, that experiences have no introspectible features that are not also contents. Representationalists hold that one piece of evidence for this is that when you pay attention to your introspecting, you find that you are only paying attention to objects and properties in the world. At no time do you encounter your experience or something that exists in yourself, as opposed to the familiar objects and properties that we take to be in the world around us. Representationalists claim that transparency evidence for the conclusion that the character of experience is exhausted by features of the world represented by experience, and, in particular, is not constituted in part by any vehicles of representation. ${ }^{14}$

Two prominent naturalistic theories of representation are the causal covariation and the teleological theory. These are held by Michael Tye and Fred Dretske, respectively. Knowing the details of these theories is important for the case I will make below, namely, that certain Gestalt switches provide a counter-example to naturalistic nonconceptual representational theories of phenomenal character. 
Michael Tye formalises the causal covariation approach thus (where $\mathrm{S}$ is a state of an object $\mathrm{x}$ ):

$\mathrm{S}$ represents that $\mathrm{P}={ }_{\mathrm{df}}$ If optimal conditions obtain, $\mathrm{S}$ is tokened in $\mathrm{x}$ if and only if $\mathrm{P}$ and because $\mathrm{P} .{ }^{15}$

If conditions are not optimal then misrepresentation can occur. For example, if I am in a state that in optimal conditions, causally covaries with there being fish present, but conditions are not optimal and there are no fish about, then my state misrepresents the presence of fish.

On a teleological theory, a state will represent some object or property if it is the function of that state to indicate (provide information about) those things. Unpacking this statement gives rise to different teleological theories. For example, Dretske holds that a state $\mathrm{S}$ represents that an $\mathrm{F}$ is present if it has been chosen by natural selection to have the function of indicating, or carrying information about, Fs. ${ }^{16}$ Another teleological theory is held by Millikan, who argues that it is the consumers' use of representations that bestow function. This utilisation of a state determines whether it is a representation and what it is a representation of. ${ }^{17}$

\section{Ambiguous Figures: Introduction}

There are some two-dimensional figures and three-dimensional objects that can be seen in two sharply distinct ways. Consider the following three examples:

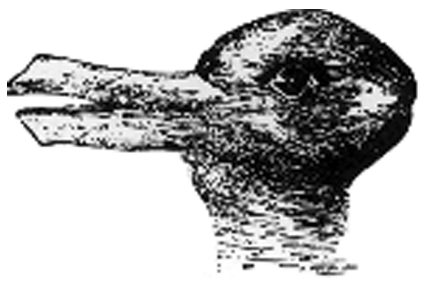

Duck/Rabbit Picture

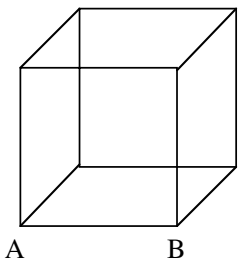

Necker Cube

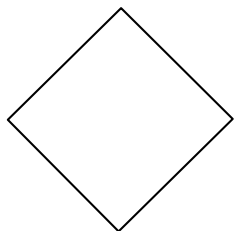

Square/Regular Diamond

The duck/rabbit picture can be seen either as a picture of a duck or as a picture of a rabbit. The Necker cube can be seen so that the line AB is on the front plane of the cube or on the back plane. The square/regular-diamond picture is such that initially one sees the figure as a regular diamond, but one can also see it as a square. 
The switch from seeing the pictures in one way to seeing them in the other way happens suddenly, due to the saccadic nature of our visual perception, and is known as a Gestalt switch. It is most prominent in the Necker-cube example. The switching is, to some extent, under our control. It is also impossible to see the figures in both configurations simultaneously. Intuitively, what is happening when one undergoes the Gestalt switch is that one's visual experience changes. One has an experience with one phenomenal character and then one has an experience with a different phenomenal character. (I believe that this is a correct description of the phenomenon, however, I will discuss challenges to this conception of ambiguous figures in the next section.)

One might question whether when viewing the square/regular-diamond figure one really undergoes a Gestalt switch. Certainly, the case is not quite as vivid an example as the Necker-cube case. I believe it is a case, nonetheless, and I want to establish this with certainty because it is this example, and examples of a very similar kind to it, that will prove problematic for the representationalists' account.

The square/regular-diamond figure was first cited as a type of ambiguous figure by Mach in 1897 and is commonly held to be such by other authors. ${ }^{18}$ I mention that others hold this figure to be ambiguous because whether a figure is, or is not, ambiguous depends upon consensus among seeing creatures, and the consensus says that they are. Despite this, the claim that the square/ regular-diamond figure is ambiguous can be backed up by evidence that does not rely on intersubjective agreement regarding introspection. The psychologist Stephen Palmer considers the figures below and claims:

when a square is rotated 45 degrees, it is generally perceived as an upright diamond rather than as a tilted square. Now, if shape constancy were perfect, as presumably it would be were only invariant features detected, these two figures would be seen as rotational variants of the same shape. Their shapes are often not seen as the same, however, at least not in the same sense that, say, upright and 45-degree 'A's are seen as the same shape in different orientations. ${ }^{19}$

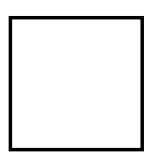

Square

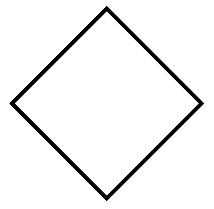

Regular Diamond

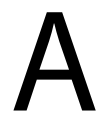

Rotated As

Palmer holds that lack of shape constancy is actually quite pervasive. It holds among crosses and plus signs, and the direction in which equilateral triangles are seen to point. 

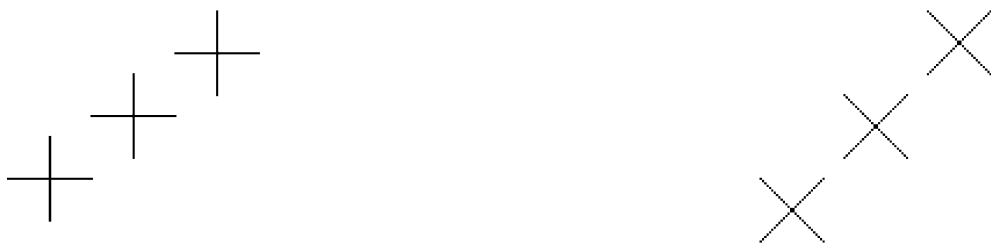

$+/ \mathrm{x}$ in conditions that bias perceived shape

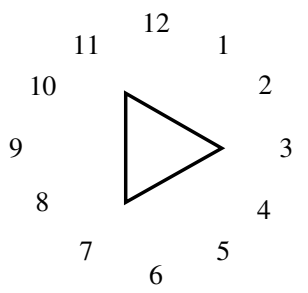

Direction equilateral triangle points to (3, 7 or 11 o' clock) yields ambiguity

The evidence that backs up the view that the square/regular diamond is an ambiguous figure, and different from the rotated 'A's, comes from Rock's and Wiser's work on recognition of rotated objects. ${ }^{20}$ As Palmer reports, their studies show that when certain objects are initially presented in one orientation in space and then re-presented in another orientation, people have difficulty recognising them as the same objects in the second presentation. Palmer claims that this effect is seen when objects do not have one "good intrinsic axis" crosses/pluses have no one good intrinsic axis, this places them in a different category from other shapes with such a good intrinsic axis (such as 'A's).

I have noticed that not all shapes that lack one good intrinsic axis are liable to be ambiguous. What seems to mark out those shapes that have no one good intrinsic axis and are liable to be ambiguous is that they have a small number of equally good axes. (The square/diamond and cross/plus have two; the equilateral triangle has three.) Having multiple equally good axes is not a sufficient condition for ambiguity because a regular many-sided figure, such as an octagon, has a large number of equally good axes (eight) and is not ambiguous. Nor is having such axes a necessary condition for ambiguity, as the duck/rabbit picture exemplifies. What I hope to have shown, however, is that there is some good reason, which comes from experimental evidence on shape constancy, that shows that figures with no intrinsic axis, but a small number of equally good axes, elicit different reactions when presented in 
different orientations in space compared with other figures. Thus, in addition to evidence from our own introspection, there is good reason to hold that the square/diamond figure, and other similar figures, really are ambiguous.

It should be noted that although the orientation of a square may affect whether it is more likely to be perceived as a square or a regular diamond, this is not the only relevant factor. For example, in the illustrations below, although the figures' orientation would suggest that they would be seen as regular diamonds, the surrounding features make them more likely to be perceived as squares:
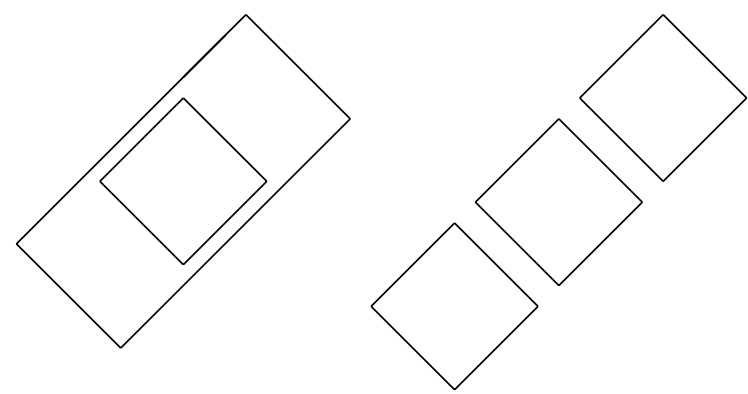

Moreover, as any square/regular diamond can be ambiguous, we know that orientation does not fix how things look; it only affects which perception is more likely.

\section{Ambiguous Figures and Changes in Phenomenal Character}

Most authors on the subject are agreed that the phenomenon of Gestalt switching involves having two different experiences with different phenomenal characters. For example, the representationalist Michael Tye says of the face/vase ambiguous figure:

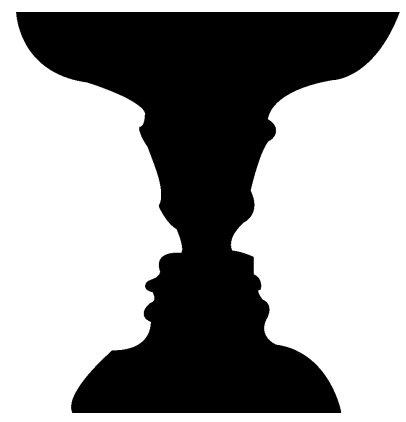

a distinction can be drawn between the phenomenal character of the experiences one undergoes when one sees the figure below as two faces and the experience one has when one sees it as a vase. $^{22}$ 
Similarly, Alan Millar claims:

The relation between experience and recognition has featured prominently in discussions of ambiguous figures ... It is characteristic of such examples that as one looks at the drawing one sees it first in one way and then in another. Moreover, the changes in ways of seeing are genuinely visual. ${ }^{23}$

The psychologist Richard Gregory claims that when looking at ambiguous figures one's "perceptions" change, though the stimulus input remains constant. He makes it is clear that by 'perceptions' he means conscious experiences with phenomenal character. ${ }^{24}$

I mention that these other philosophers and psychologists hold that there is a genuine difference in experience in these cases because in part the evidence that one must appeal to here is introspective and the more people that agree that a change takes place in their experience the better. However, while I agree with them, some people might be inclined to attribute the change that we recognise when we view an ambiguous figure, not to a change in experience, but rather to a change judgement - either a judgement about what one sees, or a judgement about one's experience (or both). The idea would be that, for example, seeing a square as a square and then as a diamond did not involve experiences with different phenomenal characters, but instead only involved differences in the categorising, cognising or conceptualisation of the object. $^{25}$ In this section, I argue that this position is untenable.

The position is untenable for two reasons. First, not all changes in judgement appear to lead to the special changes that occur in perceptions of ambiguous figures. Consider the case of the square/regular diamond in comparison to the rotated 'A's.
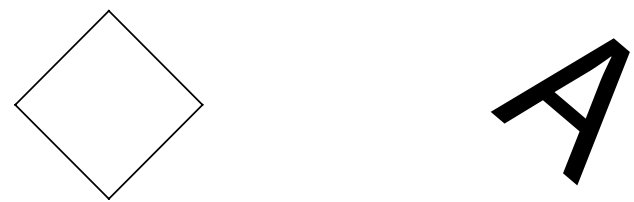

Judging the figure on the right to be a tilted 'A', as opposed to a figure that is not tilted, does not mean that one undergoes the distinctive Gestalt switching phenomenon, which one experiences when looking at the left hand figurenothing one does can make one undergo a Gestalt switch with respect to the 'A'. Therefore, a change in judgement is not sufficient to generate the special changes experienced in Gestalt switches, and thus cannot constitute the change that we experience when we undergo the Gestalt switch. Another example makes the same point. Indeed, it makes it even more forcefully because in this example there is no question that we can and do have the judgements in question. Many optical illusions persist in spite of our judgements. For example, in the Müller-Lyer and Ponzo illusions, lines continue to look of unequal 
length even when one has measured the lines, knows the nature of the illusion, and knows that the lines are of equal length. ${ }^{26}$ Thus, often our judgement is not sufficient to bring about a perceptual change.

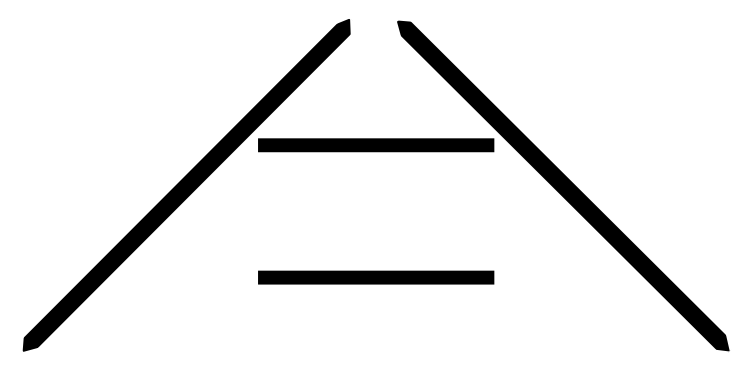

The Ponzo Illusion: the top horizontal line looks longer than the bottom one.

Secondly, although one can have a certain autonomy over the Gestalt switching phenomenon, it often happens outwith your control. Sometimes the Necker cube changes when you are trying to avoid a change. Sometimes you try to make the change happen and you cannot. Similarly, consider the triangles below. One sees them all, or clusters of them, pointing in the same direction. This direction can change. To try to make it change you need to focus on one triangle and imagine that it is pointing in another direction. If it changes, the surrounding triangles appear to spontaneously change with it. Moreover, it is impossible to see the triangles as all randomly pointing in different directions. ${ }^{27}$ This seems to suggest that the visual system has a certain autonomy and a certain modus operandi that is quite unlike ordinary judgement.

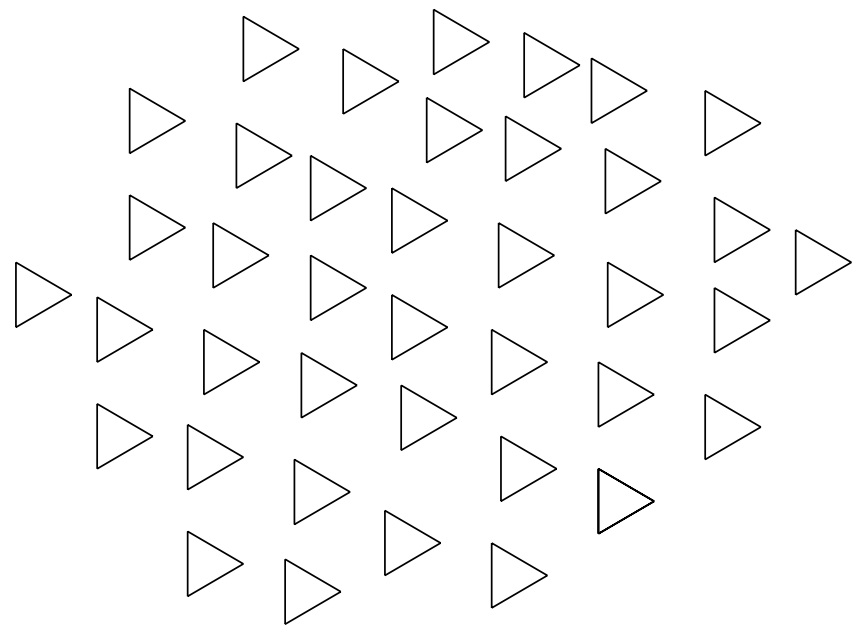


The changes that occur when a Gestalt switch happens really seem to be changes in visual experiences. Indeed, this is why ambiguous figures, especially the more dramatic examples, are such interesting phenomena. In the next section, I will begin to examine whether the representationalist theory can account for these changes in the phenomenal character of the experiences of ambiguous figures.

\section{Ambiguous Figures: A Preliminary Challenge}

If one accepts the results of the last section, then what happens when one undergoes a Gestalt switch is that, while looking at the same stimulus, one has an experience with a certain phenomenal character followed by another experience with a different phenomenal character. Those representationalists that hold that phenomenal character is identical with, or determined by, the nonconceptual content of experience have to account for the difference in the experiences before and after the Gestalt switch by supposing that there is a difference in the nonconceptual content of the experiences.

What difference in content could there be between the experiences before and after a Gestalt switch? The obvious way to express the difference would be in terms of how the experiences strike the subjects of the experience. For example, in the duck/rabbit picture, one experience might have the content that a duck-form is present, while the other has the content that a rabbitform is present. Similarly, in the case of the square/regular-diamond picture, one experience represents that a square shape is in front of one, the other that a regular-diamond shape is in front of one.

Amplification of this explanation, however, might lead one to suspect that the relevant content here might be conceptual, rather than nonconceptual, content. If the content of the experiences is different, in virtue of the fact that it seems to subjects of these experiences that a duck-form or a rabbit-form or a square shape or a regular-diamond shape was present, and one held that the way an experience seems to a subject is tied to a subject's cognitive and conceptual abilities, then content ascribed on this basis would fit the specification for conceptual content. ${ }^{28}$

If this were correct, one might worry that ambiguous figures threaten to undermine the representationalists' identification of phenomenal character with nonconceptual content, on the grounds that one must invoke conceptual content to account for the Gestalt switch (and therefore a difference in conceptual content accounts for the change in phenomenal character). To explain: one might think that someone could not see the picture as a picture of a duck unless they recognised that it looked like a duck and were prepared to judge that something duck-like was present. One might also think that having such recognitional and judgmental abilities requires one to possess, or amounts to one possessing, the concept of a duck. Therefore, one might think that to undergo the Gestalt switch in response to the duck/ 
rabbit picture, someone must see the picture as a duck and then as a rabbit (or vice versa) and this requires the person to possess the concepts of a duck and of a rabbit. If one needs to possess the concepts of a duck and of a rabbit to undergo the Gestalt switch, then one might suppose that a difference in nonconceptual content between the experiences will not account for why the subject has to possess the relevant concepts to experience the change in phenomenal character. This observation seems to undermine the theory that the nonconceptual content of visual experiences is identical with, or determines, the phenomenal character of those experiences.

There are two different types of response that a representationalist might make in order to uphold the claim that nonconceptual content alone accounts for the phenomenal character of experiences.

The first agrees with one tenet of the position stated above, namely, that in order to undergo the Gestalt switch one must see the picture as a duck and then as a rabbit (or vice versa) and this requires the possession of the concepts 'duck' and 'rabbit'. For example, Michael Tye claims that to have an experience with the phenomenal character that one has when one sees the picture as a rabbit, one might indeed have to possess the concept of a rabbit, but he claims this concept might not form part of the content of the experience. This is possible because a concept may cause a certain state with particular nonconceptual content to be tokened. He says:

Where a figure has an ambiguous decomposition into spatial parts, concepts can influence which decomposition occurs. This is one way in which top-down processing can make a phenomenal difference. But once a particular decomposition is in place, the way in which an ambiguous figure phenomenally appears is fixed ... One cannot see something as a rabbit, for example, unless one has the concept rabbit. Likewise, it cannot appear to one that there is a rabbit by the hat unless one has the concepts rabbit and hat. What happens in cases like these is that one has a sensory representation whose phenomenal content is then brought under the given concepts. Still, the concepts do not enter into the content of the sensory representations and they are not themselves phenomenally relevant. ${ }^{29}$

Therefore, the difference in phenomenal character when seeing the picture as a duck and seeing it as a rabbit may be due to different nonconceptual states being tokened, even if such states are caused by the conceptual abilities of the subject of those states.

An alternative reply, and one that has the virtue of explaining why certain recognitions, judgements or conceptual states occur, accepts the claim that to see a picture as a duck one must possess the concept of a duck. Nevertheless, it resists the claim that in order to undergo a Gestalt switch, such as the one had when looking at the duck/rabbit picture, one has to possess the concept of a duck and the concept of a rabbit. Alan Millar, a 
proponent of this kind of position, claims that it is by no means clear that when one undergoes a Gestalt switch one has to recognise the picture first as being of one form, then as being of another, in any sense of 'recognise' that implies bringing the picture under a concept. He thinks it is plausible that the switch in the phenomenal character of the experiences is what enables subjects who possess the appropriate concepts to bring the picture first under one concept, say, picture of a duck, then under the other, say, picture of a rabbit. Different phenomenal characters would trigger different conceptual capacities of a subject, if they had those capacities, so that they would see, and/or judge, that first a picture of a duck was present and then subsequently that a picture of a rabbit was present. If a creature lacked those capacities, they would not see the picture as a picture of a rabbit, although they may have an experience with the same phenomenal character as someone who does. ${ }^{30}$

It does seem possible that creatures lacking the relevant concepts could undergo Gestalt switches. Many ambiguous visual stimuli consist of drawings on a two-dimensional plane that represent either two- or threedimensional objects. ${ }^{31}$ One piece of evidence that infants appear able to perceive what drawings and pictures in general represent comes from Granrud and Yonas's experiments. They showed that infants between the age of five and seven months can detect and use pictorial cues of overlap, familiar size, relative size, shading, linear perspective, and texture gradients. ${ }^{32}$ At the same time, it seems implausible that infants possess such complex concepts. Another piece of evidence comes from Slater and Morison's findings on shape constancy and slant perception at birth. They demonstrated that infants of a few days old could reliably perceive planar shapes, such as triangles and squares, and could perceive a shape as the same shape in spite of changes in surface slant and orientation. ${ }^{33}$ Further, Ralph Haber reports:

the reasonable likelihood is that scene perception comes first, then as soon as one aspect of scene perception can be accomplished (whether with or without the need of experience), that same aspect can be performed on pictures without further experience. The classic study by Hochberg and Brooks (1962) tested an eighteen-month old child who had never been exposed to any two-dimensional representations. When asked to identify familiar objects, he was as accurate in doing so from pictures and from drawings of the objects as he was when seeing the objects themselves . . no prior experience with pictures seemed necessary. ${ }^{34}$

I know of no study that directly investigates whether creatures that lack the relevant concepts can perceive Gestalt switches, but there seems no reason in principle why they could not. ${ }^{35}$ Indeed, one can readily imagine an experiment designed to test this. Millar describes a hypothetical experiment where a child that lacked the concepts of a duck and of a rabbit was 
tested to see if they underwent a Gestalt switch. ${ }^{36}$ Suppose the child displayed curiosity when it encountered rabbits and fear when it encountered ducks. It seems possible that when shown the duck/rabbit ambiguous picture, the child would show fear on some occasions and curiosity on others. This would be evidence for the claim that the child could see the picture first in one way and then in another.

One worry about such a test would be whether one could plausibly maintain that a child lacked the concepts of a duck and of a rabbit if the child could respond in a way that suggested it could see the picture in different ways. Millar responds to this worry by taking a 'high-grade' view of concepts:

Clearly in our thought experiment the duck-form has a certain significance for the child - it prompts fear. But a disposition to experience fear on having a certain type of sensory experience hardly amounts to a conceptual capacity ... I favour the view that to possess a concept is to have a patterngoverned capacity to form, maintain, and evaluate beliefs whose contents include the concept. ${ }^{37}$

There are some philosophers who might have a 'lower-grade' view of concepts than Millar. They might think that displaying a recognitional capacity for an object suffices to show that one has a concept of that object, and therefore that Millar's experiment does not test for evidence of Gestalt switches without the relevant conceptual abilities. There are two ways to respond to this. The first is to question whether the child really needs to possess recognitional capacities for duck-forms or rabbit-forms in order to display fear in the presence of duck-forms and curiosity in the presence of rabbit-forms. ${ }^{38}$ This is because the child may not be able to uniquely respond in one way to all and only duck-forms and in another way to all and only rabbit-forms. For example, they may always express fear in response to duck-forms but also to a variety of other things, such as goose-forms, cow-forms and frog-forms. Yet, as long as they always displayed fear in the presence of duck-forms and curiosity in the presence of rabbit-forms, their different reactions to the duck/rabbit picture could show that their experience of it changes.

The second way to respond to the worry that one could only undergo a Gestalt switch if one had recognitional abilities pertaining to what was seen is to consider how one acquires recognitional abilities at all. It seems plausible to think that in order to gain a recognitional, or even a discriminatory, capacity there must be differences manifest in experience that one can learn to recognise or discriminate between. ${ }^{39}$ If this is so then there must be experiences that differ in some ways, despite this not being in a way that demands conceptual capacities. Thus, it seems quite plausible that Gestalt switches could occur without conceptual capacities coming into play. 
In conclusion, in this section I have explained why the phenomenon of Gestalt switching appears to present a prima facie problem for the view that phenomenal character is identical with, or is determined by, nonconceptual content. This is because one might think that the change in phenomenal character can only be explained by a difference in conceptual content. I have shown that nonconceptual representationalists could claim that certain concepts are required to undergo a switch, but only because they are required in order to cause a particular nonconceptual state to be instantiated. Alternatively, they could claim that only a change in nonconceptual content is required in order for one to undergo a Gestalt switch - concepts are not required. These two replies leave open the possibility that the change in phenomenal character could be accounted for by some change in nonconceptual content.

In the next section, I will show that, while the changes in phenomenal character in the duck/rabbit and Necker-cube cases could be explained by a change in nonconceptual content, the case of the square/regular diamond is recalcitrant to this type of analysis. This is certainly the case if one holds that some naturalistic account of representation should be accepted. Then, in section seven, I will look at some possible responses to this problem and argue that they fail to account for all changes in phenomenal character associated with Gestalt switches.

\section{Ambiguous Figures: The Second Challenge}

The representationalist must say that the two different experiences had when looking at an ambiguous figure must have two different nonconceptual contents to explain the difference in phenomenal character. Two nonconceptual contents, A and B, have to be identified. A and B will, however, be specified using concepts, therefore, one has to ensure that the nonconceptual contents picked out by $\mathrm{A}$ and $\mathrm{B}$ are genuinely different nonconceptual contents. To do this one must make a plausible case for how an experience might come to have one of these nonconceptual contents and not the other.

In the duck/rabbit and Necker-cube cases, specifying the differences in content between the two experiences that one can have while viewing the pictures, and showing how experiences could come to have those contents in accord with some naturalistic theory, will be reasonably straightforward. This is because there are independent occurrences of ducks and rabbits, and cubes in different orientations, that correspond to the two contents in question. We can readily understand how an experience could covary with, or have the function of indicating, ducks as opposed to rabbits because of the possibility of their independent occurrence. When one sees a picture of a duck or a rabbit the content of those experiences will not straightforwardly be 'rabbit' or 'duck' but perhaps something like, 
'duck-looking', or 'rabbit-form' or 'picture of a duck'. Whichever, the thought that, say, 'duck-form' and 'rabbit-form' can be genuinely different contents can be made sense of because there can be something duck-like present without something rabbit-like present.

Matters are not this straightforward, however, in the case of the square/ regular diamond. Every time a square shape is present, a regular-diamond shape is also present, because a square is a regular diamond. How could an experience covary with one and not the other, or be caused by one and not the other? How could an experience have the function of indicating one and not the other? Therefore, how can we be persuaded that an experience can have nonconceptual content pertaining to a square and not, at the same time, have nonconceptual content pertaining to a regular diamond?

That this is a substantial problem for a nonconceptual theorist can be seen by considering the causal covariation and the teleological theories of content in turn. Recall Michael Tye's formulation of the causal covariation theory (where $\mathrm{S}$ is some state of an object $\mathrm{x}$ ):

$\mathrm{S}$ represents that $\mathrm{P}={ }_{\mathrm{df}}$ If optimal conditions obtain, $\mathrm{S}$ is tokened in $\mathrm{x}$ if and only if $\mathrm{P}$ and because $\mathrm{P}$.

Suppose one tried to give an account of the difference between a square representation and a regular-diamond representation based on Tye's definition. When optimal conditions obtain, a state $(\mathrm{S})$ that represents a square will be tokened in a subject (x) if and only if a square is present and because a square is present. However, every time a square is present a regular diamond is present and will equally be a cause of the representation, on the grounds that a square is a regular diamond. Thus, a square representation will also be a regular-diamond representation. The conditions required for a state to represent a square, as opposed to a regular diamond, are not met. Ambiguous figures show that there is a need to distinguish between representing that a square is present and representing that a regular diamond is present, but it looks as if the causal covariation theory does not have the resources to do so.

One objection to this conclusion comes from noting that one might think that the causal covariation theory can account for the ability of a state to represent a square and not a regular diamond by holding that the relata of causal relations are fine-grained. Thus, for example, one might hold that causal relata are facts and that facts are as finely grained as the contents of propositional attitudes. On this view, the fact that a square is present is a different fact from the fact that a regular diamond is present even though these two facts will be made true by the same coarse-grained state of affairs.

To respond to this objection it is first worth summarizing very briefly the different views that have been held on the nature of causal relata. The 
different views about how fine-grained causal relata are range over a spectrum: there is a variety of more or less fine-grained views. Thus, some views would hold causal relata to be states of affairs, others would hold them to be events (where events are individuated by their associated <object, property, time $>$ triples) and others still would hold them to be facts. Even within these views there are different opinions about how finely individuated events or facts are, which thus yield different accounts of the fineness of grain of the causal relata. ${ }^{40}$ For example, within the events view, there are questions concerning how finely grained one should take properties to be. (Are they individuated as abundantly as predicates or are they sparse and individuated in accordance with the joints of nature?) Within the facts view, one could take facts to be Russellian or as finely grained as Fregean propositions.

Without going too much into the details of the debate concerning the nature of causation, there are three reasons to be sceptical of the success of the above objection. First, the argument that causal relata need to be more fine-grained than coarse-grained states of affairs has been resisted by Davidson and Strawson. ${ }^{41}$ They argue that the notion of cause is ambiguous between a non-intensional notion of causation and intensional notion of causal explanation. They hold that the need for fine-grained relata only applies to the notion of causal explanation. If this is right, then, as the causal covariation theory of representation clearly has the notion of causation in mind and not causal explanation, it still cannot distinguish between representing that a square is present and representing that a regular diamond is present. Secondly, one can allow that causal relata are finely grained enough so as to allow that the event of Hamish's walking is a different causal relatum to the event of Hamish's walking briskly, without thereby supposing that the relata must be as finely grained so as to allow that the event of a regular diamond coming to be in your visual field is a different causal relatum from the event of a square coming to be in your visual field. Thus, one can account for one of the major examples that have persuaded people that causation must relate things more finely grained than states of affairs without holding that causal relata must be as finely grained as the contents of propositional attitudes. Thirdly, there are two substantial worries about whether someone who is trying to provide a naturalistic theory of representation can plausibly endorse an account of causation that relates facts that are as finely grained as the contents of propositional attitudes. The first is that if an account of representation claims that we must invoke the notion of causation, and, furthermore, that account has to spell out the notion of causation by mentioning that it relates things as finely grained as the propositional attitudes, then there is a worry that the theory is circular. That is, there is a worry that the notion of causation employed relies on the notion of propositional attitude content, and that is itself a species of representation, which is the very notion that we are trying to give an 
account of. Second, even if this first line of thought is resisted on the grounds that such an account is not problematically circular, either because the circle is wide enough to be explanatorily illuminating or because it is claimed that, although facts are individuated by the contents of propositional attitudes, they are nonetheless mind and representation independent, still, this account of facts has to claim that all these different finely grained, mind-independent facts exist and have (in many cases different) causal powers. It is not clear to me that an account of the existence of such facts can be given in a naturalistic spirit of the kind invoked by those who advocate naturalistic theories of representation.

I will return to consider the causal covariation theory further below, but, for now, I will consider whether the teleological theory fares any better. A teleological theory claims that a state will represent some object or property if and only if it is the function of that state to indicate that object or property. Two main theories of what it is for a state to have a function are Dretske's evolutionary account and Millikan's consumers' use account, both outlined above.

This theory can explain why a duck-form experience is different from a rabbit-form experience on the assumption that these states have different functions. It is plausible to think that they have different functions because it is plausible to think that these states could contribute differently to a creature's selective fitness. Similarly, it is not difficult to see how these representations could have different uses by a consumer of those representations.

When one turns to consider the case of square/regular diamond, it looks prima facie as if teleological theories will fail to distinguish having a function to represent that squares are present from having a function to represent that regular diamonds are present. If something has a function to represent that squares are present, does it not thereby have a function to represent that regular diamonds are present? How could evolution select a state because it carries information about squares, and not because it carries information about regular diamonds, when it seems that any selective advantage that information about squares would endow would equally be endowed by information about regular diamonds, because squares are regular diamonds? Similarly, any use by a consumer of a state that represents squares would equally be use of a state that represents regular diamonds. Anything that a square's presence could facilitate, a regular diamond's would also, because a square is a regular diamond.

It can be noted that this problem regarding accounting for different nonconceptual contents of perceptual experience bears a striking resemblance to one raised by Martin Davies concerning causal covariation and teleological theories of meaning. Davies says: 
on the face of it, causal covariation and teleology will not distinguish, for example, between meaning that Hesperus is thus-and-so and meaning that Phosphorus is thus-and-so, or between meaning that water is thus-and-so and meaning that $\mathrm{H}_{2} \mathrm{O}$ is thus-and-so. Indicating the state of Hesperus is just the same as indicating the state of Phosphorus, and a need for water is just the same as a need for $\mathrm{H}_{2} 0{ }^{42}$

One might have thought that a theory of nonconceptual content could avoid this problem, precisely because it is a theory of nonconceptual perceptual representation. The content of perceptual experience is frequently held to be limited to observational features and properties. Thus, one might have thought that a theory of perceptual representation does not have to account for the difference between Hesperus and Phosphorus or water and $\mathrm{H}_{2} \mathrm{O}$, as this type of content never features as the content of visual experiences. $^{43}$ Even if it is true that perceptual content is so limited, however, squares and regular diamonds are clearly observational features. Nonetheless, they provide us with the kind of problematic example in the perceptual case that Hesperus and Phosphorus provide in the case of meaning.

One might also have thought that the problem Davies outlines does not arise in the case of perceptual experience because such experiences cannot have two different nonconceptual contents that should be specified using different concepts that have the same reference. ${ }^{44}$ Yet, as our ambiguous figures show, if one identifies phenomenal character with nonconceptual content then one must suppose that there is some change of nonconceptual content when undergoing a Gestalt switch, and so the representationalist must be able to account for the difference in nonconceptual content between an experience associated with seeing Mach's figure as a square and the experience associated with seeing Mach's figure as a diamond. (I will call these a square-type experience and a diamond-type experience from now on for ease of exposition. In general, an F-type experience is an experience such that in the absence of countervailing circumstances it would seem to you as if an $\mathrm{F}$ were there if you possessed the concept of an F.)

As we have seen, the problem that the square/regular-diamond ambiguous figure poses arises because there cannot be two distinct states of the world, one of which corresponds to square representations, the other of which corresponds to regular-diamond representations. One way to address this problem would be to try to find a property or relation that is represented when a square is represented but not when a regular diamond is represented. As long as there are some states in the world that exemplify this property or relation, and some that do not, then one could use this fact to explain the representational difference, even if the square/regulardiamond ambiguous figure necessarily has both properties. That is to say, 
although any property a square has a regular diamond also has, perhaps one property is represented when one has a square-type experience that is not represented when one has a regular-diamond-type experience.

In the next section I will examine whether this type of response is viable.

\section{Looking for Appropriate Properties}

Christopher Peacocke gives an account of the difference between representing a square and representing a regular diamond along the lines suggested at the end of the previous section. He claims that, to account for many ambiguous figures, two separate levels of nonconceptual content have to be distinguished. ${ }^{45}$ It should be noted that Peacocke does not argue that nonconceptual content can account for all phenomenal character, nor does he hold any particular theory of representation. However, he does try to account for the different experiences had when viewing a square/regular-diamond ambiguous picture by identifying and citing differences in nonconceptual content. Peacocke distinguishes between scenario nonconceptual content and protopropositional nonconceptual content. I will now examine whether this strategy can be put to use by the representationalists I have been discussing.

Peacocke identifies some of the content of experience with a 'scenario'. Peacocke states that a scenario is a spatial type, "individuated by specifying which ways of filling out the space around the perceiver are consistent with the representational content's being correct" ${ }^{46}$ According to Peacocke, the difference between seeing something as a square and seeing it as a regular diamond cannot be captured at the level of scenario content. That is to say, a regular-diamond-type experience and a square-type experience have the same scenario content.

Peacocke invokes protopropositional content to account for the different experiences involved in this Gestalt switch. A protoproposition contains an individual or individuals, and a property or relation. An experience has protopropositional content when it represents the individual or individuals in question as having a particular property. Peacocke claims that protopropositional content is nonconceptual and contains properties and relations such as curved, parallel to, equidistant from, same shape as and symmetrical about. ${ }^{47}$

According to Peacocke, protopropositional content explains why we see a regular diamond as different from a square, because when we see a square our experience has the protopropositional content that there is symmetry about the bisectors of the shape's sides. When we see the same object as a regular diamond, our experience has the protopropositional content that there is symmetry about the bisectors of the shape's angles. ${ }^{48}$

To use Peacocke's strategy, the representationalist has to hold that when we have a square-type experience, symmetry about the bisectors of the sides is 
represented, and, when we have a regular-diamond-type experience, symmetry about the bisectors of the angles is represented. Because there are sometimes distinct and separate occurrences of these properties (there are shapes with only side bisector symmetry and shapes with only angle bisector symmetry), the causal covariation or teleological theory might be able to account for these differences in representation, and so the difference in phenomenal character could be explained by a difference in nonconceptual content. ${ }^{49}$

I hope to show, however, that different symmetries do not suffice to explain the square/regular-diamond ambiguous figures nor other similar ambiguous figures.

Consider why, in the case of ambiguous figures, there is a characteristic Gestalt switch such that one can either see the picture as one thing, or another, but not both. One cannot see, for example, the Necker cube as two cubes with different orientations at the same time. An excellent explanation in terms of nonconceptual content would be that the visual system either could not, or was such as to avoid (as far as possible), representing a set of inconsistent nonconceptual contents. One might argue also that the visual system was such as to maximise the representational interpretation. In other words, the visual system was such that it aimed for maximum consistency and completeness.

If nonconceptual contents were such that the visual system tried both to maximise the total content and to avoid inconsistency then this would help to explain why two different experiences could be had when looking at the Necker cube. In this case, there are two different maximally complete and consistent contents that can be formed in response to it, and thus we can have two distinct visual experiences.

This explanation will not do, however, for the square/regular-diamond ambiguous figure, for there are not any inconsistent contents when having a square-type experience and a regular-diamond-type experience. Having the content, 'is symmetrical about the bisectors of its sides' is not inconsistent with having the content, 'is symmetrical about the bisectors of its angles'. One can understand why, if a particular scenario content was compatible with two different maximally complete and consistent sets of protopropositions, then there would be a sudden shift between the two phenomenal characters. In the case of the square and the regular diamond, however, there appears to be no reason why one's experiences could not have both contents concerning the different types of symmetry. So why do they fail to do so? Must they fail to do so? Protopropositional contents do not allow us to answer this question.

Further, consider that it seems perfectly possible to see a square as a square while focusing intently on its angle bisector symmetry, as the diagram below indicates. 


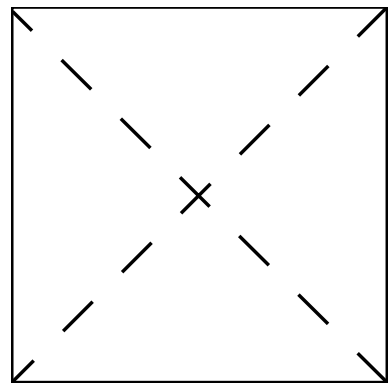

To see this property of the square, is it not the case that the content pertaining to angle bisector symmetry must feature in the content of one's experience? If so (as I believe it to be) then this is a case where content pertaining to both types of symmetries are present in one's experience. Therefore, a further content would be required to distinguish seeing Mach's figure as a square, while focusing on its angle bisector symmetry, from seeing Mach's figure as a regular diamond, while focusing on its line bisector symmetry. Content regarding different symmetries would not distinguish the different phenomenal characters of these experiences. Therefore, content regarding symmetries does not appear to distinguish the phenomenal characters of all experiences associated with seeing a figure as a square and seeing it as a regular diamond.

Additionally, not all ambiguous figures of simple shapes are symmetrical at all. Consider the figures below:

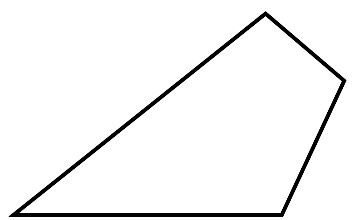

Distorted Square

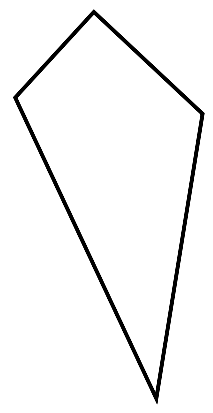

Kite

In the same way that the square/regular diamond was ambiguous, these figures are ambiguous. The distorted square can be seen as a kite and vice versa. Note that similar to the square/regular-diamond figure, these figures have more than one good intrinsic axis, although this is not an axis of symmetry. These figures are equally problematic for the representationalist 
theory because, like squares and regular diamonds, there is no occurrence of a kite shape in the world without the occurrence of a distorted-square shape. ${ }^{50}$ In these cases, because the figures lack symmetry, there are no axes of symmetry to feature in the contents of the different experiences that one can have in response to the figures. Thus, axes of symmetry featuring in the content do not explain the different phenomenal characters of the two experiences.

Moreover, Stephen Palmer, a psychologist who has studied these types of figures extensively in the laboratory, used to hold that symmetry could explain ambiguity in symmetrical ambiguous figures, but he is no longer as confident. ${ }^{51}$ The reason is that the symmetry theory predicts that only symmetrical contextual factors will bias the way in which perceivers see objects. In a study utilising equilateral triangles, however, Palmer has shown that, rather than only symmetric contextual factors influencing shape perception, both symmetric and non-symmetric contextual factors have an influence. Moreover, some symmetrical contextual factors have very little influence, indeed much less than other non-symmetrical factors. ${ }^{52}$

Thus, content regarding symmetries does not seem to differentiate the ambiguous figures under discussion. To look for another solution, one might ask whether there was some other content that could be had by the square-type experience and not by the regular-diamond-type experience.

One might think that the difference between the experiences is that in one a square is represented and in the other a diamond is represented, but not a regular diamond. One might think that the content of the experience associated with seeing the figure as a diamond is less determinate than the content of the experience associated with seeing the figure as a square.

Evidence that supports this supposition comes from a psychological study carried out by Ferrante, Gerbino and Rock. They claim that people can accurately judge whether an angle is a right angle or not when the angle is normal, that is when the lines forming the angle are seen as close to the horizontal and vertical axes. People cannot accurately do this when the angle is not normal. ${ }^{53}$

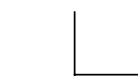

Normal Right Angle

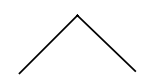

Non-Normal Right Angle

This would suggest that when people have experiences associated with seeing the figure as a square their experience contains the content that right angles are present. This is not the case when a person has an experience associated with seeing the figure as a diamond. Ferrante, Gerbino and Rock themselves say: 
The effect of orientation on the perception of a right angle can be subsumed under the broad category of the effect of orientation on phenomenal shape. Indeed it provides at least a partial explanation of what was perhaps the first demonstration of this kind of effect, namely the example by Ernst Mach (1887) of the different appearance of a square when rotated 45 degrees; it then looks like a diamond. ${ }^{54}$

While this would appear to be an excellent explanation of the difference in content that a nonconceptual representationalist could appeal to in order to explain the change of phenomenal character in the square/regulardiamond ambiguous figure, it would not appear to explain the following ambiguous figure:

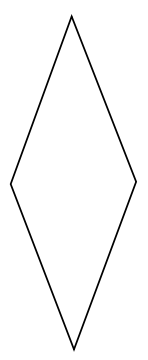

Non-Regular Diamond

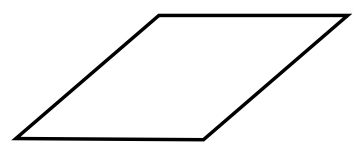

Parallelogram

The non-regular diamond/parallelogram ambiguous figure has no right angles or angles close to right angles. The angles are plainly very acute or very oblique. The effect of perception of right angles as a singularity in the normal case cannot play a role in the ambiguity of these figures. Similarly, in the case of the ambiguity of the direction that an equilateral triangle points, the explanation regarding right angles can have no role to play.

The conclusion one reaches is therefore that, while the differing phenomenal characters of the experiences had in response to the square/regulardiamond figure could be explained by a difference in nonconceptual content relating to the rightness of angles, the experiences had in response to the above ambiguous figure, and the ambiguity of equilateral triangles, could not be explained in this way. We have two counter-examples to representationalism. There is a difference in phenomenal character between the experiences that one can have when looking at these pictures that cannot be explained by a difference in nonconceptual content.

A defender of representationalism might now try to improve on the strategy employed by Ferrante, Gerbino and Rock to account for ambiguous figures. It might be thought that their strategy can be generalised 
in the following way. In the case of the square/regular-diamond figure, it was suggested that one first saw the angles of the figure in a normal position and then one saw them as not normal. In order to do this, one must be imposing a framework - a set of perpendicular axes labelled top/bottom, or up/down, and left/right - within, or upon, our experience. These axes can be imposed upon the figure irrespective of the actual orientation of the figure with respect to the viewer. Perhaps these axes can be imposed upon any figure, whether it has right angles or not. If so, one could make a case for the idea that our phenomenally different experiences of all the problematic ambiguous figures discussed above would have different contents. ${ }^{55,56}$
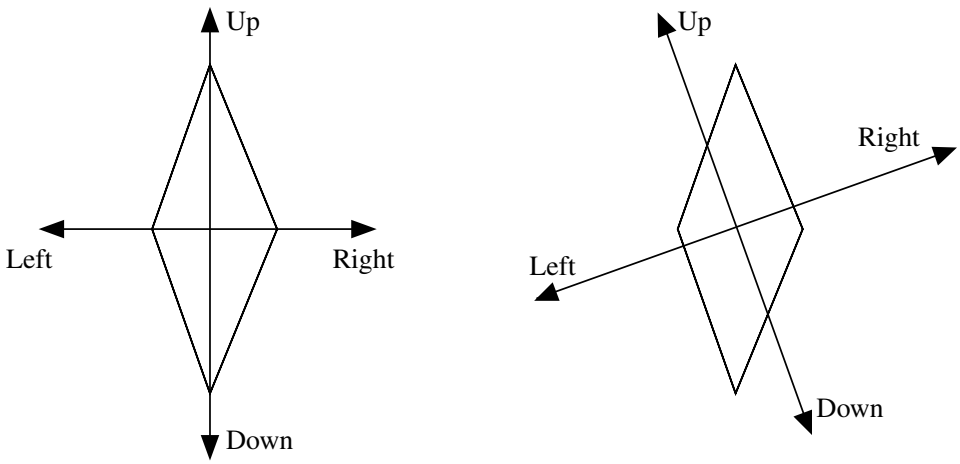

In the diagram above, different axes have been superimposed over the same non-regular diamond figure. A representationalist might claim that experiences corresponding to each of the two figures would represent different properties. For example, the experience corresponding to the first figure would represent an angle pointing in the direction of 'up'. In the experience corresponding to the second figure, this would not be represented. Instead, two sides of the figure would be represented as being parallel to the up/down axes. Thus, with these different viewer-imposed properties represented in each case, it could be plausible to hold that the experience corresponding to the first figure represents a non-regular diamond and the experience corresponding to the second figure represents a parallelogram. A representationalist could hold that these differences in representation account for the differences in phenomenal character associated with the two ways of seeing this figure. ${ }^{57}$

This third representationalist strategy, however, faces a problem. The problem arises by noting that very many figures are not ambiguous. In section four, one example was given of a non-ambiguous figure that displayed shape constancy: an 'A'. This empirical fact would be problematic if one assumed the following: (i) one can impose more than one set of axes on all figures, and, (ii) as in the case of ambiguous figures, the resulting 
experiences that represented different things would have different phenomenal characters. On these assumptions, the representationalist cannot account for the fact that there are some non-ambiguous figures, but, clearly, they must be able to do this or their theory would be failing to account for shape constancy, which is a pervasive feature of our experience. ${ }^{58}$ To do this they must explain either why only one set of axes can be imposed upon certain figures (the non-ambiguous ones) and why more than one set can be imposed upon other figures (the ambiguous ones), or they must explain why the experiences that represent different properties do not give rise to experiences with different phenomenal characters in non-ambiguous figures, but do so in the other ambiguous figure cases. ${ }^{59}$

The explanations that the representationalist must provide either have to pick out some feature of ambiguous figures that makes them different from non-ambiguous figures or have to identify some feature of how we represent ambiguous figures that makes them different from how we represent nonambiguous figures. In other words, this strategy of claiming that we can impose sets of axes within our experience has to be complemented by some further claim that points to a difference between ambiguous and nonambiguous figures or a difference in how we represent them. Once this is appreciated, we could modify Peacocke's symmetry proposal and Ferannte, Gerbino and Rock's right-angle proposal and use them as different proposals that attempt to specify either the conditions under which different sets of axes can be imposed upon a figure or the conditions under which representational differences will entail phenomenal differences. We could treat Peacocke's proposal as saying that either you can only impose more than one set of axes when there is more than one type of axes of symmetry present in a figure or that the only representational differences (relating to subjectively imposed up/down and left/right axes) that will entail a phenomenal difference are those that represent different types of axes of symmetry as being parallel to the subjectively imposed up/down and left/right axes. We could treat Ferannte, Gerbino and Rock's proposal as saying that either you can only impose two sets of up/down and left/right axes when one set of axes will make a right angle a normal angle and when another set will make the angle non-normal or that only subjectively imposed directional axes that differ in whether they make a right angle normal or not will entail a phenomenal difference in the resulting experiences. Of course, we saw that neither of these answers was adequate to account for all ambiguous figures. The proposal in hand, that there are different sets of axes that we can impose, however, needs to be supplemented with a suggestion of this type in order that we can understand why some figures are ambiguous and some are not, that is, understand why imposing different sets of axes either is only possible in the case of ambiguous figures or only leads to the special changes in phenomenal character that we find in ambiguous figures. 
To summarise, the suggestion that different subjectively imposed frames of reference would yield experiences with different contents has been under consideration. It was found that while this suggestion yielded the required result, namely, that experiences of ambiguous figures could be seen to have different representational contents, the suggestion, nonetheless, was flawed. This was because the suggestion did not provide constraints specifying either how many different subjective frames of reference can be imposed on any figure or did not specify the principles whereby some, but not all, representational differences entail phenomenal differences. Thus, this suggestion had the unintended and unfortunate consequence that it predicted that we should be able to have (perhaps many) phenomenally different experiences of all figures, that is, that all figures should turn out to be ambiguous. However, we know this to be false. Therefore, whether the representationalist wishes to invoke subjectively imposed frames of reference or invoke an account that does make reference to them, such as Peacocke's, the same type of explanation is required from them to explain ambiguous figures. We have seen that it has not as yet been forthcoming. This explanation must either say something about why there are two (or more) ways for experience to represent ambiguous figures, and only one way for experience to represent non-ambiguous figures, or it must say why the different ways of representing ambiguous figures entails that the relevant experiences have different phenomenal characters, while the different ways of representing non-ambiguous figures does not entail that the relevant experiences differ in their phenomenal character.

At this point, it might be supposed that my conclusion is hostage to empirical fortune. It may be suggested that psychologists will one day discover which phenomenally relevant representational differences exist between the different experiences of each ambiguous figure and why experiences of non-ambiguous figures fail to exhibit these differences. Therefore, perhaps we have simply not yet determined what the crucial differences in content are that obtain between the two experiences that one can have of the ambiguous figures in question. Thus, while a representationalist cannot name the relevant difference in representation between the different experiences of ambiguous figures, they can be confident that there is one.

While it seems that this outcome is a possibility, it is by no means a certainty. There are three reasons for this. First, one could simply doubt whether an explanation will ever be forthcoming in the absence of such an explanation to date. Perhaps ambiguous figures provide a straightforward refutation of representationalism. Furthermore, one of the most appealing features of representationalism is that it aims to naturalise phenomenal character. If there is no naturalistic theory of representation that has yet been formulated that can predict that there will be a representational difference between experiences of ambiguous figures, never mind predict what that difference is, then, as a theory, representationalism can be seen to 
have lost a lot of its power and its appeal. Representationalist theories not supplemented by a theory of representation provide only a possible strategy for yielding a naturalistic account of consciousness. They do not themselves provide a concrete theory; therefore, any assessment of them as naturalistic theories of phenomenal character has to remain provisional.

Secondly, one might suggest that psychologists may never be able to isolate a single feature responsible for the Gestalt switching in each particular case. There may be a large number of relevant factors that, in different combinations and in different degrees, affect the experience that one will have - such as symmetry, orientation, the surroundings of the figure, global elongation, axes of symmetry, etc. In this case, it is not clear that the differences in one's experiences had when looking at an ambiguous figure can readily be explained by a difference in content. What would that content be when there are so many factors that influence one's experiences to varying degrees?

Thirdly, psychologists may find one crucial factor that influences how we experience such shapes but this factor might be similar to the factor that was first proposed in the case of the square/regular diamond, namely, symmetry about the bi-sectors of sides or angles. Recall that it seemed plausible to suppose that one can see a square as a square (and, therefore, according to this theory to have one's experience represent symmetry about the bi-sectors of the sides) and, at the same time, pay attention to the symmetry about the bi-sectors of the square's angles (thus making it plausible that one's experience contains content pertaining to this too). This possibility stopped this factor from providing the explanation of the representational difference between seeing Mach's figure as a square, while focusing on the angle bisector symmetry, and seeing Mach's figure as a regular diamond, while focusing on the side bisector symmetry. It can therefore be seen that the explanatory feature that psychologists identify may be a feature that, when one pays attention to it, one cannot help but suppose one's experience contains content pertaining to it. If this were so, the crucial factor that determines how an ambiguous figure looks would not have its influence simply in virtue of whether or not it is it represented in experience. Rather, there might be a difference between experiences of the same ambiguous figure according to which content is being attended to or focused on and which content is merely implicit in one's experience (that is, which content one's experiences has that does not depend for attention on its existence). $^{60}$

In short, while such options remain, the onus is on the representationalist to convince us that ambiguous figures can be adequately accounted for by the different contents of experience.

\section{Conclusion}

I have argued that naturalistic, nonconceptual, representationalist theories of phenomenal character cannot account for the changes in the phenomenal 
character of one's experiences associated with some ambiguous figures. I have also tried to show why these theories are the most plausible versions of representationalism. I first showed that experiences with two different phenomenal characters could be had in response to one stimulus. I argued that there was good reason to think that in general one did not have to invoke conceptual content to explain the different experiences one can have when looking at an ambiguous figure. Then I argued that the experiences had when viewing ambiguous figures were problematic for representationalists who hold causal covariation and teleological theories of representation when there could not be two distinct occurrences of the apparently different shapes that seemed to be seen.

Peacocke's solution, namely, that representational differences can occur at the level of protopropositional contents regarding different symmetries, looked like the correct strategy to pursue. Yet, it seemed to leave unexplained several elements of the square/regular-diamond picture, such as why one cannot be in a state with both symmetry protopropositional contents. I suggested that you can see Mach's figure as a square and as having symmetry about the bisectors of its angles, and thus it appears that there is not the representational difference that Peacocke proposes between all the different experiences associated with the square/regular diamond. Moreover, the kite/ distorted-square ambiguous figure (amongst others) poses the same problem for the representationalist as the square regular-diamond figure. However, because it is not symmetrical, content relating to symmetry cannot distinguish a distorted-square-type experience from a kite-type experience.

I then explored the suggestion that the nonconceptual content of a squaretype experience might be more determinate than the content of the experience associated with seeing a figure as a diamond. This was backed by empirical evidence that shows that people can judge angles to be right-angles much more accurately when they look as if they are normal angles. As there can be occurrences of right angles without occurrences of non-right angles, this suggestion would seem to allow the representationalist to explain the difference in content between the square-type experience and the diamond-type experience. However, this explanation would not explain other cases of equally problematic ambiguous figures such as the non-regular diamond/ parallelogram figure and the equilateral triangle, for these figures do not contain right angles or angles close in degree to a right angle.

Finally, I explored the suggestion that differences in content between experiences of ambiguous figures could exist because there can be different sets of axes imposed subjectively within, or upon, experience. While this suggestion predicted that there would be differences in the content of experiences of ambiguous figures, it also seemed to predict that this would be the case for non-ambiguous figures. To refute this apparent consequence an explanation has to be given of either how ambiguous figures differ from nonambiguous figures or how the content of the experiences that represent them 
differ. No such explanation has been forthcoming, and I gave some reasons to doubt that a good explanation exists. Therefore, I conclude that there are some changes in phenomenal character that cannot be accounted for by the naturalistic, nonconceptual representationalist. The claim that one can provide a naturalistic account of phenomenal character by theorising that it is identical to, or determined by, noncenceptual content is put in doubt. ${ }^{61}$

\section{Notes}

${ }^{1}$ This terminology is famously used by Nagel (1974).

${ }^{2}$ See Cussins (1990) and Bermudez (1995). It should be noted that Peacocke (1994) has defined the notion of conceptual content directly as one that is composed of concepts. However, the drawback of this definition is that it rules out the possibility of there being a conceptual content not composed of concepts. It is plausible that there could be such conceptual content: content understood along Russellian lines.

${ }^{3}$ See also Macpherson (2003) and (2005).

${ }^{4}$ See Tye (1995) and (2000) and Dretske (1995).

${ }^{5}$ It should be noted that what is distinctive about representationalism is not that it ascribes contents to perceptual states per se (many theories do this) but that it holds that content is related to phenomenal character in the way described in the text.

${ }^{6}$ See Peacocke (1992).

${ }^{7}$ This notion of content with regard to visual experiences is explicated by amongst others Martin (1994), McGinn (1982), Millar (1991) and Peacocke (1983). Tye (1995) p. 104 also claims that seeing as or seeing that involves being able to remember or recognise that which is seen, and thus plausibly requires conceptual abilities. Dretske (1995) pp. 10-11 and 67-68 recognises this conceptual conception of seeming that or seeing that or being conscious that and calls it the doxastic or epistemic sense. He takes this to be the 'normal' way to interpret the phrase, however, he holds that there is also a non-doxastic sense of the term.

${ }^{8}$ See Tye (1995) and Raffman (1995). The point applies to many perceptible qualities, such as perception of pitch, loudness, length, etc.

${ }^{9}$ This is frequently done in developmental psychology. See Bermúdez (1995) and my discussion of Granrud and Yonas's experiments in section 5.

${ }^{10}$ See Crane (1992) for an extended discussion of these, and other, examples, of how belief content differs from experiential content.

${ }^{11}$ It is common amongst nonconceptual representationalists to think that beliefs have no phenomenal character and that, to the extent that it is true to say that there may be something it is like to believe something, this should be explained by a belief being accompanied by a state that does have phenomenal character, for example, an emotion or visual image. See, for example, Tye (1995) p. 4. However, there is an opposing position. This position does not challenge representationalism per se, but it presents a challenge to nonconceptualist versions of it, if one supposes belief states to lack nonconceptual content. The opposing position is advocated by Block (1995) p. 230, Chalmers (1996) pp. 9-10, Siewart (1998) pp. 263-306 and Strawson (1994) pp. 5-13.

${ }^{12}$ This is Tye's way of stating representationalism: "Phenomenal character is one and the same as a certain sort of intentional content" (1995) p. 137 and "the phenomenal character of such experiences ... is identical with, or contained within, their intentional contents" (1995) p. 136. The intuitive thought to have here would be that having a certain content is a property of an experience and that having a certain phenomenal character is also a property of experience and that these two properties are the same. In a later work, Tye (2000) is more specific about why he holds that phenomenal character and content are identical. He states that neither phenomenal character nor representational content are qualities of experience. Rather, they are things that an 
experience "has" pp. 48-49. He notes, "representational content is not a quality of the thing that has representational content" (2000) p. 49. Further, he claims that when a subject has a visual experience they are aware of qualities of external surfaces and not qualities of experience. It is being aware of these qualities of external surfaces that is to count as being aware of phenomenal character (p. 49). What they are aware of is thus the content of the experience. Alex Byrne (2002/2003) is critical of Tye's metaphysics here and thinks that it is preferable to hold that phenomenal character is the property of an experience in virtue of which there is something that it is like to undergo that experience. He then identifies this property with the property of having a certain content. Byrne's way of explicating the identity claim here seems preferable.

${ }^{13}$ See Tye (1995) pp. 134-137.

${ }^{14}$ See Tye (1995) pp. 135-137 and Dretske (1995) chapter 2.

${ }^{15}$ Tye claims, "The conditionals in this definition should be understood subjunctively. So the definiens is to read as follows: If optimal conditions were to obtain, $\mathrm{S}$ would be tokened in $\mathrm{x}$ if and only if $\mathrm{P}$ were the case; moreover, in these circumstances, $\mathrm{S}$ would be tokened in $\mathrm{x}$ because $\mathrm{P}$ is the case". See Tye (1995) p. 223.

${ }^{16}$ See Dretske (1995) chapter 1.

${ }^{17}$ See Millikan (1993) chapter 4.

${ }^{18}$ See Mach (1897), Peacocke (1992), and Palmer (1983) and (1992).

${ }^{19}$ Palmer (1983) p. 292. 'Shape constancy' refers to the common phenomenon where the perceived shape of an object remains constant despite changes in the shape of its retinal projection caused by the movement of the object relative to the observer. 'Invariant features' of an object are those that do not change when the object is moved. In a simple rigid object, these would include number of right angles, the number of straight sides, etc.

${ }^{20}$ See Rock (1973) and Wiser (1981).

${ }^{21}$ Palmer (1983) holds that an intrinsic axis is generated by bilateral symmetry and/or global elongation.

${ }^{22}$ Tye (1995) p. 140.

${ }^{23}$ Millar (1991) p. 37.

${ }^{24}$ Gregory says what changes in a Gestalt switch are "phenomenal phenomena". See Gregory (1997) p. 195 and p. 227.

${ }^{25}$ It must be emphasised that the view under consideration is distinct from the view that phenomenal character itself involves a judgmental or conceptual element. The view I am considering here is that one's judgement changes and one's experience does not. This is distinct from the view that one's experience changes on account of one's judgements or conceptual states changing. This latter view will be considered in the section below.

${ }^{26}$ An explanation and diagram of the Müller-Lyer illusion is above in section 1.

${ }^{27}$ This phenomenon is discussed in the psychological literature. See Attneave (1968) and especially Palmer (1992).

${ }^{28}$ Several philosophers insist that an experience is such that it seems to a subject that an $\mathrm{F}$ is there if and only if they would believe that an $\mathrm{F}$ is there in the absence of countervailing considerations and, thus, only if they possess the concept of an F. See section 2, especially footnote 6 .

${ }^{29}$ Tye (1995) p. 140.

${ }^{30}$ This is Millar's strategy in outline. See Millar (1991) pp. 39-42.

${ }^{31}$ Gregory, however, describes a three-dimensional wire Necker cube that one can see in two ways even when one is touching it. He states, "When the cube reverses, the visual and touch spaces separate: the faces of the cube appear in one place but are felt in another. This is a curious experience". See Gregory (1970) chapter 3. In Gregory (1997) p. 207 there is also a photograph of a porcelain figure that is ambiguous between a duck and a rabbit.

${ }^{32}$ Granrud and Yonas's experiments are reported in Goldstein (1996) pp. 277-281.

${ }^{33}$ The infants are said to have achieved 'shape constancy'. See Slater and Morison (1985).

${ }^{34}$ See Haber (1983) pp. 217-218. 


\section{NOÛS}

${ }^{35}$ Related experiments have been carried out by Gopnik and Rosati (2001). They investigated preconditions for undergoing Gestalt switches. It seems that while most 5-year-old children can experience Gestalt switches, most 3-year-old and 4-year-old children cannot. Moreover, they found that the ability to perceive Gestalt changes is strongly correlated with the ability to understand that other people may have different beliefs about an object compared with oneself, or that one's own beliefs about an object might change. In addition, they found that there was a strong correlation between undergoing Gestalt switches and having an abstract understanding of the notion of pictorial ambiguity. Two points need to be noted here. While children may have to be conceptually sophisticated in the ways indicated by these experiments to undergo Gestalt switches, it does not show that they need to possess concepts pertaining to the two interpretations of the ambiguous figure to do so. Secondly, this experiment tested whether children could undergo a Gestalt switch and report the characteristic phenomenal shift that takes place during the time that one is looking at the ambiguous picture. However, it has not been shown that on two separate viewings children could not interpret an ambiguous picture in one way on the first occasion and then in the other on the second, even if they did not possess the conceptual sophistication which Gopnik and Rosati's experiments suggest is necessary for experiencing a Gestalt switch during the time one is looking at a picture. It is the ability to see a picture in two different ways, rather than the more specific ability of being able to see it in two ways during the one viewing of the picture, that is the more pertinent condition when it comes to assessing whether how one sees something must be governed by one's conceptual capacities pertaining to what is seen. Moreover, the case of undergoing a Gestalt switch during one viewing of a picture and the case of seeing the same picture on two different occasions in different ways present exactly the same challenge to representationalism. Thus, Gopnik and Rosati's results are of little value in determining the facts pertinent to our question.

${ }^{36}$ Millar (1991) p. 39.

${ }^{37}$ Millar (1991) p. 39.

${ }^{38}$ I use the term 'duck-form' to refer to a duck-like shape or image which would be present both when a duck was present and when a drawing or picture of a duck was present. The same applies, mutatis mutandis, to the term 'rabbit-form'.

${ }^{39}$ Dretske (1981) chapter 6, Martin (1994), and Smith (2002) chapter 3 argue persuasively for this point.

${ }^{40}$ See Schaffer (2003).

${ }^{41}$ See Davidson (1967) and (1970) and Strawson (1985).

${ }^{42}$ Davies (1995) p. 290.

${ }^{43}$ Tye (1995) p. 141, for example, claims that the nonconceptual contents of experience will be limited in this way. The idea is that perceptual content is limited to representing size, shape and colour.

${ }^{44}$ In his latest statement on perceptual representation, Tye explicitly denies that belief (conceptual) representation and perceptual (nonconceptual) representation involve the same sort of intensionality. He denies that nonconceptual representation can involve different modes of presentation and presents several reasons why one should think that this is so. See Tye (2000) pp. 54-60. Peacocke, by contrast, has recently claimed that there is an intuitive notion of 'mode of presentation' that applies to nonconceptual perceptual content. However, Peacocke's argument should not persuade us. The type of example that Peacocke uses to motivate the idea that nonconceptual perceptual content can involve modes of representation is the very type of example that we are here questioning, namely, cases like the square/regular-diamond case. Peacocke holds that experience can have different modes of presentation because he assumes that differences in experiences of Mach's figure must be differences in content. See Peacocke (2001) pp. 240-241. Thus, from the point of view of this article, which seeks to question representationalism, Peacocke's argument begs the question. Thus, independent reasons are required to hold that nonconceptual content can involve modes of presentation. Moreover, a representationalist solution to the problem of ambiguous figures that tried to hold that the 
experiences of Mach's figure can have content that differs only in mode of presentation ought to show that the proposed solution is naturalistic. I believe that to do this one would either have to provide a new, plausible theory of naturalistic nonconceptual perceptual content (no mean feat) or one would have to provide the kind of detailed account examined in section seven below that specifies specifically the way experiences might differ in content. Without showing that such a solution is naturalistically possible the mere existence of the formal possibility of a solution being found in this manner is hardly a solution at all. This is especially the case when (a) naturalistic theories of perceptual content to date do not admit the possibility of experiences differing only in mode of presentation, (b) no other type of examples motivate the need for nonconceptual modes of presentation, (c) Tye, a leading representationalist, has independent reasons for holding that there are no nonconceptual modes of presentation.

${ }^{45}$ See Peacocke (1992) chapter 3.

${ }^{46}$ Peacocke (1992) p. 61.

${ }^{47}$ See Peacocke (1992) p. 77.

${ }^{48}$ Peacocke cites Palmer (1983) as a source for this idea.

${ }^{49}$ For instance, the causal covariation theorist might try to hold that conditions are not optimal for viewing some symmetries when looking at an ambiguous figure. The teleological theorist might try to hold that a square-type experience has never come to have the function of indicating symmetry about the bisectors of the sides.

${ }^{50}$ Of course, there can be kite shapes that are not squares that have been physically distorted, but this is not what I mean here. I have chosen these names simply as they seem to me to best describe how the figures appear in their different Gestalts.

${ }^{51}$ Note the change between Palmer (1983) and Palmer (1992).

${ }^{52}$ See Palmer (1992).

${ }^{53}$ Ferrante, Gerbino and Rock (1997). The effect they describe is independent of whether the image projected onto the retina forms a normal right angle or not relative to the horizon (or some other standard), rather, it depends on whether the subjects would judge the angle to be normal.

${ }^{54}$ Ferrante, Gerbino and Rock (1997) p. 169.

${ }^{55}$ A brief history of psychologists who have posited the idea of subjectively imposed frameworks - reference frames - is given in Palmer (1992) pp. 44-45.

${ }^{56}$ It should be noted that the causal covariation or teleological theories of representation outlined above cannot provide, as they stand, an account of such content. These theories would have to be substantially modified to do so. I shall assume, in this part of the paper, that a suitable naturalistic account of this type of content could be found (although finding one would not, I believe, be a trivial task).

${ }^{57}$ The case of the equilateral triangle cannot be treated exactly like the case of the nonregular diamond/parallelogram. This is because the obvious way to impose three different sets of axes to account for the fact that equilateral triangles can be seen in three different ways (along the three axes of symmetry) does not yield different geometrical relations between the axes and aspects of the figure. However, I believe modifications can be made to the same general strategy to achieve the same result. One could relate, for example, the triangle and the axes to some other object. Such an object could be another seen object or it could be the perceived orientation of one's body or the perceived orientation of gravity. It does not seem implausible to think that viewer-relative properties can be represented in experience; one obvious example includes 'being to the left of'.

${ }^{58}$ The notion of shape constancy in explained in footnote 19 .

${ }^{59}$ Indeed, the representationalist would also need an explanation of why any particular ambiguous figure could only be seen in the limited number of ways that it can be (typically two or three). They would need to explain why only two or three different frameworks can be imposed or why only two or three sets of such frameworks yield experiences with different 
phenomenal characters. I will not dwell on this further complication in the rest of the paper, but it is one that is worth noting.

${ }^{60}$ I have written elsewhere about the idea that there are different levels of content in experience and made some suggestions concerning what effect such levels might have on the phenomenal character of experience. See Macpherson (1999).

${ }^{61}$ I would like to thank Alan Millar, José Luis Bermúdez, Agustin Rayo, Stephen Butterfill and Martin Doherty for their helpful comments and discussion.

\section{References}

Attneave, F. (1968) - "Triangles as Ambiguous Figures", in American Journal of Psychology, 81, pp. $447-453$.

Bermúdez, J. L. (1995) - "Nonconceptual Content: From Perceptual Experience to Subpersonal Computational States", in Mind and Language, 10, pp. 333-369.

Block, N. (1995) - "On a Confusion About a Function of Consciousness", Brain and Behavioral Sciences, 18 , pp. 225-247.

Byrne, A. (2002/2003) - "DON'T PANIC: Tye's Intentionalist Theory of Consciousness", A Field Guide to the Philosophy of Mind, book symposium on Consciousness, Color and Content, Winter 2002/2003, http://host.uniroma3.it/progetti/kant/field/tyesymp.htm.

Chalmers, D. J. (1996) - The Conscious Mind, Oxford: Oxford University Press.

Crane, T. (1992) - "The Nonconceptual Content of Experience", in T. Crane (ed.), The Contents of Experience: Essays on Perception, Cambridge: Cambridge University Press.

Cussins, A. (1990) - "The Connectionist Construction of Concepts", in M. Boden (ed.), The Philosophy of Artificial Intelligence, Oxford: Oxford University Press.

Davidson, D. (1967) - "Causal Relations", reprinted in his Essays on Actions and Events, Oxford: Clarendon Press, 1980.

Davidson, D. (1970) - "Mental Events", reprinted in his Essays on Actions and Events, Oxford: Clarendon Press, 1980.

Davies, M. (1995) - "The Philosophy of Mind", in A. C. Grayling (ed.), Philosophy, Oxford: Oxford University Press.

Dretske, F. I. (1981) - Knowledge and the Flow of Information, Oxford: Basil Blackwell.

Dretske, F. I. (1995) - Naturalizing the Mind, Cambridge, MA: MIT Press.

Ferrante, D., Gerbino, W. and Rock, I. (1997) - "The Right Angle", in I. Rock (ed.), Indirect Perception, Cambridge, MA: MIT Press.

Goldstein, E. B. (1996) - Sensation and Perception, California: Brooks/Cole.

Gopnik, A. and Rosati, A. (2001) - "Duck or Rabbit? Reversing Ambiguous Figures and Understanding Ambiguous Representations", Developmental Science, 4:2, pp. 175-183.

Gregory, R. L. (1970) - The Intelligent Eye, London: Weidenfeld \& Nicholson.

Gregory, R. L. (1997) - Eye and Brain: The Psychology of Seeing, Princeton, NJ: Princeton University Press.

Haber, R. N. (1983) - "Stimulus Information and Processing Mechanisms", in J. Beck, B. Hope and A. Rosenfeld (eds.), Human and Machine Vision, New York: Academic Press.

Hochberg, J. and Brooks, V. (1962) - "Pictorial Recognition as an Unlearned Ability: A Study of One Child's Performance", American Journal of Psychology, 75, pp. 624-628.

Mach, E. (1897/1959) - The Analysis of Sensations, translated by C. M. Williams, New York: Dover.

Macpherson, F. (1999) - "Perfect Pitch and the Implicit/Explicit Distinction", Anthropology and Philosophy, 3, pp. 89-101.

Macpherson, F. (2003) - "Novel Colours and the Content of Experience", Pacific Philosophical Quarterly, 84, pp. 43-66. 
Macpherson, F. (2005) - "Colour Inversion Problems for Representationalism", Philosophy and Phenomenological Research, 70, pp. 127-152.

Martin, M. G. F. (1994) - "Perceptual Content", in S. Guttenplan (ed.), A Companion to the Philosophy of Mind, Oxford: Basil Blackwell.

McDowell, J. (1982) - "Criteria, Defeasibility and Knowledge", in Proceedings of the British Academy, 68, pp. 455-479.

McDowell, J. (1994) - Mind and World, Cambridge, MA: Harvard University Press.

McGinn, C. (1982) - The Character of Mind, Oxford: Oxford University Press.

Millar, A. (1991) - Reasons and Experience, Oxford: Clarendon Press.

Millikan, R. G. (1993) - White Queen Psychology and Other Essays for Alice, Cambridge MA: MIT Press.

Nagel, T. (1974) - "What Is It Like to be a Bat?", in Philosophical Review, 83, pp. 435-451.

Palmer, S. E. (1983) - "The Psychology of Perceptual Organisation: A Transformational Approach", in J. Beck, B. Hope and A. Rosenfeld (eds.), Human and Machine Vision, New York: Academic Press.

Palmer, S. E. (1992) - "Modern Theories of Gestalt Perception", in G. W. Humphreys (ed.), Understanding Vision, Oxford: Basil Blackwell.

Peacocke, C. (1983) - Sense and Content, Oxford: Clarendon Press.

Peacocke, C. (1992) - A Study of Concepts, Cambridge, MA: MIT Press.

Peacocke, C. (1994) - "Nonconceptual Content: Kinds, Rationales and Relations", Mind and Language, 9 , pp. 419-429.

Peacocke, C. (2001) - "Does Perception have a Nonconceptual Content?", Journal of Philosophy, 98, No. 5, pp. 239-264.

Raffman, D. (1995) - "On the Persistence of Phenomenology", in T. Metzinger (ed.), Conscious Experience, Schöningh, Paderborn: Imprint Academic, pp. 293-308.

Rock, I. (1973) - Orientation and Form, New York: Academic Press.

Schaffer, J. (2003) - "The Metaphysics of Causation", The Stanford Encyclopedia of Philosophy (Spring 2003 Edition), E. N. Zalta (ed.), http://plato.stanford.edu/archives/spr2003/ entries/causation-metaphysics/.

Siewert, C. P. (1998) - The Significance of Consciousness, Princeton and Chichester: Princeton University Press.

Slater, A. and Morison, V. (1985) - "Shape Constancy and Slant Perception at Birth", in Perception, 12, pp. 707-718.

Smith, A. D. (2002) - The Problem of Perception, Cambridge, MA and London: Harvard University Press.

Strawson, G. (1994) - Mental Reality, Cambridge, MA: MIT Press.

Strawson, P. F. (1985) - "Causation and Explanation", in B. Vermazen (ed.), Essays on Davidson, Oxford: Clarendon Press.

Tye, M. (1995) - Ten Problems of Consciousness: A Representational Theory of the Phenomenal Mind, Cambridge, MA: MIT Press.

Tye, M. (2000) - Consciousness, Color and Content, Cambridge, MA: MIT Press.

Wiser, M. (1981) - "The Role of Intrinsic Axes in Shape Recognition", in Proceedings of the Third Annual Conference of the Cognitive Science Society, (unpublished).

Yarbus A. L. (1967) - Eye Movements and Vision, Trans. Haigh. New York: Plenum. 